\title{
Research dissemination and PhD thesis format at a South African university: the impact of policy on practice
}

\author{
Albi Odendaal ${ }^{* a b}$ and Liezel Frick ${ }^{\mathrm{a}}$ \\ ${ }^{a}$ Centre for Higher and Adult Education, Department of Curriculum Studies, University of \\ Stellenbosch, Stellenbosch, South Africa; ${ }^{b}$ School of Music, North West University, \\ Potchefstroom, South Africa.
}

Postal address:

Private bag X6001, Potchefstroom, 2520

$+27182852387$

\begin{abstract}
The dissemination of doctoral research is a crucial ethical, financial and status issue for universities worldwide. The publication based thesis (PBT) may encourage dissemination, but is still in definitional flux at many institutions, particularly in South Africa, especially regarding how many articles are required and the publication status of these articles. We analysed and compared the formats and publication rates of 1128 of the 1141 doctoral theses published at a South African research intensive university over a 7 year period (2008-2014). We present a theoretical frame that considers publication as independent of format. Unpublished monographs account for $41.22 \%$ and published PBT for $26.86 \%$ of the sample. Monographs where material has been published and PBT with no publications, account for $20.39 \%$ and $11.52 \%$ of the sample respectively. The article argues that these unique findings are a result of institutional policy directives aimed at addressing the specific social environment of the country.
\end{abstract}

Keywords: doctoral education, thesis format, research dissemination, publication-based thesis, monograph

\section{Introduction}

The dissemination of $\mathrm{PhD}$ research is important, both as a means of growing a research career and as an ethical imperative for researchers who use public money to conduct their research. Unfortunately the conventional monograph 'only rarely, and certainly not compulsorily, contains published work' (Wilson, 2002, p. 71). The publication based thesis (PBT), a thesis where the bulk of chapters are formatted as journal articles, can be considered a remedy for this problem. While some research has traced the publication rates of doctoral students (Dinham \& Scott, 2001; Hartley \& Betts, 2009), or of doctoral graduates who become faculty (Hasselback, Reinstein, \& Abdolmohammadi, 2012; Kyvik \& Aksnes, 2015), we have not

\footnotetext{
*Corresponding author. Email: albi.odendaal@nwu.ac.za
} 
been able to identify published research that has linked thesis format and publication rates to check the assumption that format and publication rates are indeed closely linked. This is a surprising lacuna in the literature especially considering the surge towards adopting the PBT across the world.

Research published on policy in the UK (Davies \& Rolfe, 2009), Norway (Thune et al., 2012) and Australia (Jackson, 2013) suggests that only published or submitted articles are accepted as part of the PBT in those countries, and this may indeed foster a stronger publication record. South Africa has a more varied policy environment. A review of the general academic rules relating to doctoral degrees of 10 of the 17 universities listed on the Department of Higher Education and Training's website ${ }^{1}$ revealed 2 universities that require articles to be published prior to thesis submission, 2 universities that require articles to be accepted or in press prior to thesis submission, 3 universities that allow the thesis to consist of publishable material, and 2 universities that do not mention the matter in the general rules. Even though varied processes are to be expected across disciplines (and institutions), the current definitional flux has implications for national and institutional policy, pedagogy, and assessment practices that have not been investigated and that warrant a nuanced interrogation.

At the university where data was collected for this project, the thesis may consist of or contain publishable articles. The term publishable is understood to refer to articles that are formatted as if for publication, and that are submission ready, but that have not been submitted. While local practice is shaped by policy decisions (Henkel, 1999), the impact on publication rates of policies specifying thesis format has, as far as we can ascertain, remained un-interrogated. We have found no empirical evidence that the PBT results in published outputs beyond the thesis in environments like that of South Africa. This paper therefore aims to explore the relationship between publication rates and thesis format and to develop a conceptual framework that allows for PBT to be unpublished, in line with current policy directives at our research site. The framework is site-specific, but may be used to understand dynamics at other universities that have similar policy frameworks.

The PBT takes on a variety of formats globally. Gustavii (2012) identifies the Sandwich format (a number of papers bounded by an introduction and conclusion) and the Scandinavian format (a summary thesis followed by appended papers). Sharmini, SpronkenSmith, Golding and Harland (2015) agree, and suggest a further format option, the 'PhD by publication', where the thesis consists entirely of published papers. The PBT is called by a bewildering array of names, including: hybrid thesis, compilation thesis, article based thesis, thesis by publication, thesis accompanied by publication, thesis with publications appended, thesis by portfolio (Durling, 2013; Gustavii, 2012; Niven \& Grant, 2012, Sharmini et al. 2015). The hallmark of the PBT across these various formats and names, is that it consists mostly (or totally) of discrete units, chapters that, if taken out of the context of the thesis, would still make sense. In contrast, the monograph is conventionally a continuous and extended argument over the length of the thesis. It is our argument that, rather than a binary, these options of PBT and monograph provide the poles of a continuum between totally continuous and totally discrete, within which a thesis may be located.

In addition to describing format as a continuum, in this paper we consider whether a candidate has published or not during candidature, and the relationship between publication and format. This allows for an interrogation of the assumed link between publication 
proficiency and the PBT. If we schematically represent the relationships between format and publication rates (see Figure 1), the conventional relationships of the unpublished monograph and the published PBT can be found in the bottom left and top right, while the other quadrants represent previously unexplored relationships, that of the unpublished PBT and the monograph that has been published. The rest of this paper will be devoted to showing the relationships between publication and format, using the schematic frame presented here as a heuristic.

\section{INSERT FIGURE 1 ABOUT HERE}

\section{Method}

We purposively selected a research-intensive institution that has a complete electronic repository for doctoral theses. We considered all $\mathrm{PhD}$ theses published between 2008 and 2014 for this study $(\mathrm{N}=1141)$. We excluded 8 senior doctorates, 3 theses where the electronic file was not searchable, and 2 theses where the thesis document uploaded on the repository could not be matched with institutional records, leaving 1128 theses in the dataset for analysis. All of the theses in the dataset are of a high enough standard for the candidates to have received Doctoral degrees.

Each thesis was individually coded by checking the table of contents. The introduction and individual chapters were also consulted when clarification was needed. An initial classification into monograph or PBT was done by the second author and a finer coding of chapter types, publication types and attendant detail was done by the first author. Institutional data in the form of registration and graduation dates, gender, age and nationality were added. Thesis documents were electronically searched for any self-reported publications by the thesis author. Our assumption was that authors who had published would cite their own publications or give a list of publications.

This coding process gave rise to 71 variables that describe aspects of the thesis or of publications arising from the theses. For the purposes of this paper we either used variables as coded, or created dummy variables, to describe thesis format (chapter types and number, number of publications included or appended in the thesis), publication output (are publications included in the thesis published, submitted, or prepared, are other publications listed in the thesis or bibliography, date of publication), thesis type (monograph or PBT), and demographic data (date of first registration, date of graduation). Simple tabulations and percentages of the variables and dummy variables are used to describe the data. As the data is not a sample but describes the population, and as generalisation to other universities based on this data is not possible, inferential statistics are not used in this paper.

\section{Results}

In this section we will firstly describe the continuum of continuous-discrete using data on the number of discrete units in the theses and data on chapter types contained in the theses. We will then consider data on the publications that were contained or mentioned in the theses. Finally we will consider the fit between the data and the conceptual model posited in the introduction. 
One way of establishing whether the data fits our proposed conceptual model is to consider the number of discrete units in each thesis, and whether there is indeed a continuum from completely continuous to completely discrete. Theses that had no discrete units comprised $61.08 \%$ of the dataset $(n=689)$ while those with at least one discrete unit comprised the remaining $38.91 \%(\mathrm{n}=439)$. This is not the same as the number of theses that were classified by the authors as monographs $(n=701)$ or PBT $(n=427)$. The distribution of number of discrete units per thesis, separated by our classification of the theses into monograph or PBT is shown in Table 1. Some theses classified as monographs contained discrete units, but since they also contained method, results, and discussion chapters (sometimes multiples of these) in addition to the discrete units (that were for the most part unpublished), they were considered to be monographs. These $12(0.01 \%)$ theses can be seen in the Monograph column of Table 1. In addition, it can be seen in the PBT column of Table 1 that while most PBT had 3 or 4 discrete units, there are also those that had only 1 or 2 . Our earlier theorisation that format lies on a continuum from fully continuous to fully discrete is somewhat supported by this finding, with Monographs that contain discrete units and PBT that contain fewer discrete units than the norm.

\section{INSERT TABLE 1 ABOUT HERE}

Another way to investigate the continuity or discreetness of the thesis documents is to look at chapter types, and specifically how many times a specific chapter type occurred in a thesis document. We used Introduction, Literature Review, Theory, Method, Results, Discussion and Conclusion as coding categories, and noted how many of each kind of chapter occurred in a thesis. The data are summarised in Table 2, which shows the maximum number of times a chapter type occurs in monographs or PBTs. If a thesis has, for example, 2 literature review chapters and 3 results chapters, it would be classified as having at least one chapter triplicated. It was common in monographs for multiples of the same chapter type to occur. It is less common in PBT, since the standard format (by a university directive since 2012) is an introduction, some papers, and a conclusion. If all PBT authors followed this directive all PBT would only have single chapters. However, the table shows some PBT that have duplicates, triplicates and even quadruplicates of the same chapter type. These PBT could be considered to be more continuous than the 'pure' PBTs that have fewer 'other' chapters and have, on balance, a higher proportion of discrete units.

\section{INSERT TABLE 2 ABOUT HERE}

Taking the information on discrete units and on multiple chapter types together it could be argued that our posited continuum of discrete-continuous is indeed a continuum, although it is heavily weighted to the outer formats of monograph and standard PBT. An argument could be made for the departures from the standard formats to be considered anomalies of a fairly well established binary of monograph and PBT. We suggest, however, that they are important variants where authors have decided to depart from acceptable practice. Without a close reading of each of these theses it cannot be said whether such a departure was justified, but we defend the initiative of authors to shape the narrative of their research to fit the various twists and turns that such research inevitably takes.

We now turn to consider the publications that are reported by the candidates in their thesis documents. Collectively, the theses in the dataset contained 4899 units were either published or publishable, either as part of the body of the thesis, as appendices, or in the 
bibliography. This number included traditional academic publications and other publications like patents, newspaper and magazine articles, or government reports, but excluded theses for lower degrees. A total of 1302 units (26.58\% of total number of units) were published or presented before the first registration date of the graduate and 3579 units $(73.06 \%$ of total number of units) were either published, submitted or prepared during the candidature of the graduate.

Of the 3579 units that were dated within the candidature of the graduates, 791 $(22.10 \%)$ were contained in theses classified as monographs, while 2788 (77.90\%) were contained in PBT. A noteworthy $2260(63.15 \%)$ units were published or submitted to be published during the time that the graduate was registered for their doctoral degree. The majority of this number consists of traditional academic publications. Table 3 gives a breakdown of the publication status of all publication material that candidates reported in their theses and that was published, submitted or prepared during the candidature of the graduate, separated by publication type. The table shows that prepared material makes up a considerable portion (1319 or 36.85\%) of the number of publication units dated within candidature. The overwhelming majority of these are in the form of articles that are prepared for publication but not submitted at the time of presenting the thesis. Almost all of these come from PBT, and were either included with some published or submitted articles, or, in other cases, the entire thesis consisted of unpublished material.

\section{INSERT TABLE 3 AND FIGURE 2 ABOUT HERE}

In this final section of results we present a breakdown of how the theses are distributed along the theoretical frame presented earlier. The data is presented here as two interacting binaries rather than as continua. Figure 2 schematically presents this distribution. The numbers of theses and proportions outside of the box depict theses where any material has been cited as published. Notice here the proportions of theses that would be considered monographs but where graduates have published during their candidature $(20.39 \%)$, or theses that are formatted as PBT but where no publication has taken place by the time the thesis went to print (11.52\%). This strongly supports our argument for considering publication and format separately, because these relationships are substantial and important. The unpublished monograph and the published PBT form the bulk of theses (68.08\%), but it should be noted that published PBT means that at least one of the discrete units was published, and does not include only PBT that are completely published. The figures and proportions inside the box take into consideration academic articles published during the candidature of the graduate. Here, a higher proportion of PBT have published or submitted articles than monographs (23.58\% as opposed to $14.27 \%$ ), as may be expected, but the proportion of monographs where articles have been published or submitted during candidature is substantial, and almost exactly the same as the proportion of PBT candidates who have not published anything.

\section{Discussion}

The number of candidates who chose to follow the PBT route in our dataset (433 or 38.39\%) is considerably higher than that of, for example, the UK, where only 116 individuals 
nationwide had completed a publication-based thesis by 2004 (Badley, 2009), but much lower than the $77 \%$ of candidates who follow the route Norway (Thune et al., 2012). It is likely that the requirements of publishing 6-10 articles prior to graduation may dissuade candidates in the UK from following this route. This may also explain the higher proportion of PBT in our research site, where graduation criteria are less stringent and typically require fewer papers, and allow for publishable papers to be included. On the other hand, candidates in Scandinavia are paid a stipend, and this is likely to encourage publication during candidature by extending the time that could be used for the lengthy publication process. Hartley and Betts (2009) show that publishing during candidature (for candidates who are writing a monograph) can add 4 months to the length of the study period, and this could be much longer in cases with slow journal turnaround. Students in South Africa usually do not have the leisure of waiting for these processes; there is a dearth of full-time funded doctoral positions, and between $60 \%$ and $70 \%$ of students study while they work (Cloete, Mouton \& Sheppard, 2015, p. 76), necessitating a fast turnaround time.

The question arises whether these publishable documents are of lower standard than their equivalents in other countries; can one compare a thesis where 6-10 articles have been published with one where 3 articles have been prepared for publication? A further question is whether following a route of writing a PBT without publishing is of similar rigour than writing a monograph, considering that a PBT typically has considerable repetition across chapters, and may possibly not have the internal consistency typically required of a monograph? The university regulations reviewed in the introduction do address these issues, ensuring that examination is fair, transparent and performed by recognized experts, and also insist that the thesis be marked as a unified whole, making a unique contribution to the field whether it is a PBT (published or unpublished) or a monograph. We do not question whether the work is of sufficient quality, although there is likely to be variation in the quality (see Lovitts, 2007). The flipside of the first question can also be asked, whether it is not overly demanding to require 6-10 published articles before awarding a doctoral degree? Is the doctorate that is awarded for this work the culmination of a life's task or preparation for a research career (also see Mullins \& Kiley, 2002)? The institution where the data was collected regularly features in the top echelons of South African universities in various ranking systems (flawed as they are), indicating that at least relative to other South African universities there is no compromise on quality.

The data fit the conceptual frame posited earlier with striking parsimony. The hybrid formats of monograph with publications arising, and of unpublished PBT, both form considerable proportions of the total number of theses. A total of $47.25 \%$ of all thesis authors in the dataset have published, presented or submitted some form of publishable material/research during their candidature, and this is fairly evenly split between those candidates that chose to write a monograph and those that chose the PBT route. The figures are somewhat lower when only academic articles are considered (37.85\%) and this figure favours the PBT, as would be expected. However, a fair proportion of authors of monographs published academic articles during the candidature, enough to argue that in this dataset thesis format does not seem to have a major impact on publication rates, which is a unique finding of this study. The publication rates in this dataset are lower than those found by Hartley and Betts (2009). In a survey of 58 social science graduates who did not follow the PBT route, they note that $55 \%$ of their respondents had published or submitted during candidature. This 
high proportion was, however, likely influenced by the sample taken, which relied on snowballing, open invitations to participate, and targeting authors who had mentioned that the paper was based on their thesis work.

The existence of a substantial proportion of unpublished PBT is a unique finding of this study and merits some discussion. The advantage of allowing this route must be understood in the socio-economic context of the country, where university education is not free, and a large proportion of students do not have ready access to funds. Furthermore, students are often underprepared for the rigours to be demanded of them in the course of a doctoral candidature (Cloete et al., 2015, p. 108). It is likely that for some, the shortest route to graduation is often best. Add to this the tendency for formats to become departmental or disciplinary standards (see Becher \& Trowler, 2001, particularly pp. 104-129, for some discussion along these lines), and then the phenomenon of the unpublished PBT makes some sense. Using the format without enforcing publication has some pedagogical merit in helping the candidate to learn the conventions of article preparation, even if it does not induct them into the processes of publication. It is not, however without problems, the chief of which is possible copyright infringement. As has been shown in the results presented here, large numbers of unpublished articles appear in doctoral theses, all of which are (presumably) near submission standard, and all of which are 'published' in a publically accessible online format. There is a potential conflict here with the requirements of journals, that material submitted to them should not be published elsewhere, and that the journal retains copyright of the material

published by them. Using published articles in a thesis often carries copyright issues that have to be clarified if the article prints are to be included in the online version that is freely available. The inverse also holds that the publically accessible 'unpublished' articles may come under scrutiny of the publishing houses who might argue for an infringement of their copyright requirements. This has not, to our knowledge, been commented on or investigated.

\section{Conclusion}

The novelty of some of the data presented here is to our minds directly related to policies that the university has enacted. Allowing for publishable material to be included has shaped the pedagogical practices of the supervisors and some of the choices that students make on the path to 'doctorateness'. It is unlikely that the relationship between publishing and format found in this environment would be similar in environments where the inclusion of publishable material is not allowed. Furthermore, the policy of allowing publishable material to be included also seems to negate the influence of the PBT as a vehicle for increased publication output, although it may be that some of the unpublished material will be submitted and published post-doctorally or by supervisors who drive the process postgraduation. Whether this was the intended outcome of the policy directive is a matter for discussion at the universities that allow for publishable material, our contention is that these policies are appropriate for the broader South African milieu and that they fruitfully address the student's, supervisor's and university's needs.

It would be a logical next step to trace the publication rates of doctoral candidates for 5 years after graduation, as those pursuing an academic career would doubtless try to publish 
as much and as early as possible, although evidence of post- $\mathrm{PhD}$ publication rates in education departments are not encouraging (Wolhuter, 2015). This project would have to wait, as the last candidates in this dataset only graduated in March 2015, and so the data would only be complete by the year 2020. Laurance, Useche, Laurance and Bradshaw (2013) show that when considering gender, native language, institutional prestige, date of first publication, and pre- $\mathrm{PhD}$ publication record as indicators of publication success 10 years post $\mathrm{PhD}$ in biological sciences, the number of publications at the completion of the $\mathrm{PhD}$ was strongest indicator of this form of academic success. Following their lead, and tracing the publication records of each of the doctoral candidates in this study would broaden their findings to other fields and give a sense of the impact of publishing and thesis format choice on academic career paths.

\section{Notes}

1. http://www.dhet.gov.za/SitePages/InstUniversities.aspx

\section{Notes on contributors}

Albi Odendaal trained as a classical pianist at the University of Cape Town, and obtained his Doctoral degree from the University of the Arts Helsinki. He currently works as a lecturer at the North-West University School of Music.

B. Liezel Frick is an associate professor in the Centre for Higher and Adult Education at Stellenbosch University. Her current research focuses on doctoral education, postgraduate supervision, and early career researcher development. She is particularly interested in conceptualizing and developing doctoral creativity.

\section{References}

Badley, G. (2009). Publish and be doctor-rated: The $\mathrm{PhD}$ by published work. Quality Assurance in Education, 17, 331-342. doi:10.1108/09684880910992313

Becher, T., \& Trowler, P. (2001). Academic tribes and territories: Intellectual enquiry and the culture of disciplines. Buckingham: Open University Press.

Cloete, N., Mouton, J., \& Sheppard, C. (2015). Doctoral education in South Africa. Cape Town: African Minds.

Davies, R. E., \& Rolfe, G. (2009). PhD by publication: A prospective as well as retrospective award? Some subversive thoughts. Nurse Education Today, 29, 590-594. doi:10.1016/j.nedt.2009.01.006

Dinham, S., \& Scott, C. (2001). The experience of disseminating the results of doctoral research. Journal of Further and Higher Education, 25, 45-55. doi:10.1080/03098770020030498

Durling, D. (2013). Understanding the PhD by publication. In J. B. Reitan, P. Lloyd, E. Bohemia, L. M. Nielsen, I. Digranes, \& E. Lutnæs (Eds.), Design learning for tomorrow: Design education from kindergarten to PhD. Paper presented at the 2nd International Conference for Design Education Researchers, Oslo (3, 1523-1533). 


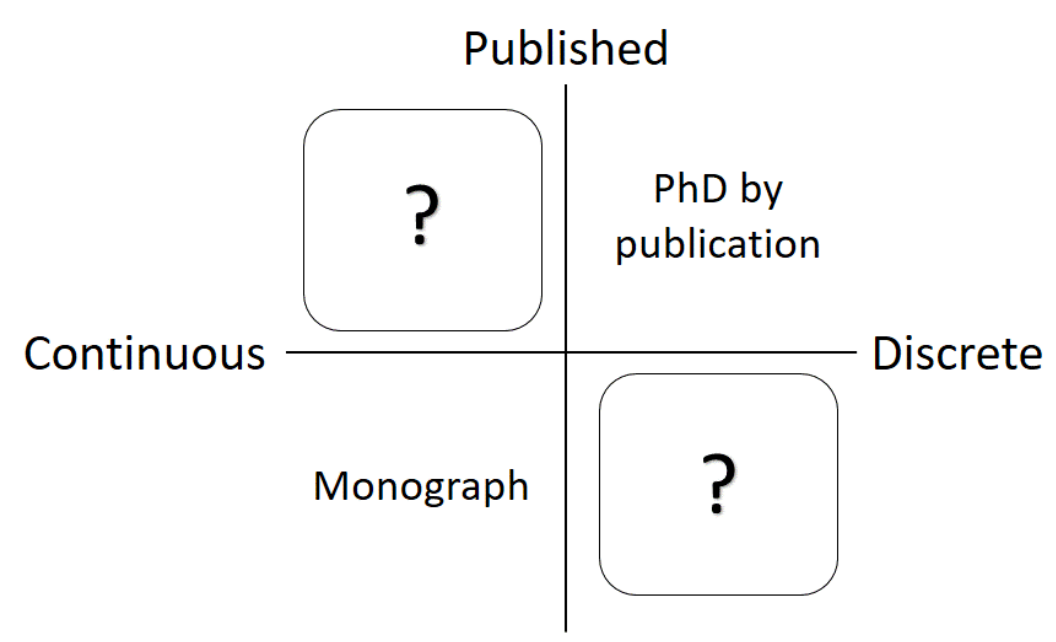

\section{Unpublished}

Gustavii, B. (2012). How to prepare a scientific doctoral dissertation based on research articles. Cambridge: Cambridge University Press.

Hartley, J., \& Betts, L. (2009). Publishing before the thesis: 58 postgraduate views. Higher Education Review, 41, 29-44.

Hasselback, J. R., Reinstein, A., \& Abdolmohammadi, M. (2012). Benchmarking the research productivity of accounting doctorates. Issues in Accounting Education, 27, 943-978. doi:10.2308/iace-50253

Henkel, M. (1999). Academic identities and policy change in higher education. London: Jessica Kingsley Publishers.

Jackson, D. (2013). Completing a PhD by publication: A review of Australian policy and implications for practice. Higher Education Research \& Development, 32, 355-368. doi:10.1080/07294360.2012.692666

Kyvik, S., \& Aksnes, D. W. (2015). Explaining the increase in publication productivity among academic staff: A generational perspective. Studies in Higher Education, 40, 1438-1453. doi:10.1080/03075079.2015.1060711

Laurance, W. F., Useche, D. C., Laurance, S. G., \& Bradshaw, C. J. A. (2013). Predicting publication success for biologists. BioScience, 63, 817-823. doi:10.1525/bio.2013.63.10.9

Lovitts, B. E. (2007). Making the implicit explicit: Creating performance expectations for the dissertation. Sterling, Va: Stylus Publishing.

Mullins, G., \& Kiley, M. (2002). 'It's a PhD, not a Nobel Prize': How experienced examiners assess research theses. Studies in Higher Education, 27, 369-386. http://doi.org/10.1080/0307507022000011507

Niven, P., \& Grant, C. (2012). PhDs by publications: An 'easy way out'? Teaching in Higher Education, 17, 105-111. doi:10.1080/13562517.2012.640086

Sharmini, S., Spronken-Smith, R., Golding, C., \& Harland, T. (2015). Assessing the doctoral thesis when it includes published work. Assessment \& Evaluation in Higher Education, 40, 89-102. doi:10.1080/02602938.2014.888535

Thune, T., Kyvik, S., Sörlin, S., Olsen, T. B., Vabø, A., \& Tømte, C. (2012). PhD education in a knowledge society: An evaluation of PhD education in Norway (No. 25/2012). Oslo: Nordic Institute for Studies in Innovation, Research and Education. 
Wilson, K. (2002). Quality assurance issues for a $\mathrm{PhD}$ by published work: A case study. Quality Assurance in Education, 10, 71-78. doi:10.1108/09684880210423555

Wolhuter, C. C. (2015). The scholarly impact of doctoral research conducted in the field of education in South Africa. South African Journal of Education, 35, 1-13. http://doi.org/10.15700/saje.v35n3a1090 